\title{
Gastric carcinoid tumours and pernicious anemia: Case report and review of the literature
}

\author{
Sarah Hagarty $\mathrm{MD}^{1}$, Istvan Hüttner MD $\mathrm{PhD}^{2}$, Henry Shibata $\mathrm{MD}^{3}$, Saul Katz MD ${ }^{1}$
}

\begin{abstract}
S Hagarty, I Hüttner, H Shibata, S Katz. Gastric carcinoid tumours and pernicious anemia: Case report and review of the literature. Can J Gastroenterol 2000;14(3):241-245. Patients with pernicious anemia are at risk of developing carcinoid tumours of the stomach. A patient with pernicious anemia and multifocal carcinoid tumours of the gastric fundus that regressed after antrectomy is presented. The frequent occurrence of gastric carcinoid tumours in patients with long-standing pernicious anemia suggests that surveillance gastroscopy and biopsies of the fundus might be indicated. Compete functional antrectomy may effectively cause these tumours to regress by removing their excessive gastrin hormonal stimulation. However, incomplete antrectomy can result in persistently elevated serum gastrin and failure of total disappearance of the carcinoid tumours.
\end{abstract}

Key Words: Antrectomy; Carcinoid tumours; Pernicious anemia

\section{Tumeurs carcinoïdes gastriques et anémie} pernicieuse : Rapport de cas et survol de la littérature

RÉSUMÉ : Les patients atteints d'anémie pernicieuse sont exposés à un risque de tumeurs carcinoïdes de l'estomac. On présente ici le cas d'un patient atteint d'anémie pernicieuse et de tumeurs carcinoïdes multifocales du fundus qui ont régressé après une antrectomie. La survenue fréquente des tumeurs carcinoïdes gastriques chez les patients ayant une anémie pernicieuse de longue date justifie le recours à des biopsies et des gastroscopies de contrôle du fundus. L'antrectomie fonctionnelle complète pourrait faire régresser efficacement ces tumeurs en éliminant la stimulation hormonale excessive causée par la gastrine. Par contre l'antrectomie partielle peut donner lieu à une persistance des taux de gastrine sériques élevés et empêcher l'élimination totale des tumeurs carcinoïdes.
$\mathrm{I}^{\mathrm{t}}$ $\mathrm{t}$ is well established that pernicious anemia (PA) is associated with an increased incidence of gastric carcinoid tumours and gastric carcinomas (1-5). The inflammation associated with the chronic atrophic gastritis (CAG) seen in PA destroys parietal cells, which impairs gastric acid secretion. The lack of acid removes the negative feedback control of gastric acid on gastrin secretion by antral $G$ cells. The resulting high gastrin levels stimulate proliferation and hyperplasia of both neuroendocrine cells of the fundic mucosa and nonspecialized epithelial cells, promoting the development of gastric carcinoid tumours and carcinomas (4).

Patients with PA have a three- to fivefold increased risk of developing stomach cancers compared with that of the general population. The incidence of carcinoid tumours in patients with PA is as high as $10 \%(3,6,7)$. Carcinoid tumours associated with CAG and high gastrin states as seen in PA are remarkable in their low malignant potential. Appro- priate therapy for such tumours is being redefined with antrectomy emerging as a good alternative to the earlier, more aggressive total gastrectomy. We present a case of regression of gastric carcinoid tumours after antrectomy in a patient with PA and type A CAG.

\section{CASE PRESENTATION}

A 64-year-old female teacher with known PA of at least 27 years' duration and hypothyroidism presented to her endocrinologist with heartburn. Her mother, also long-diagnosed with PA, had died of gastric cancer. Of two brothers with $\mathrm{PA}$, one had been recently diagnosed with colon cancer and the other with a benign colonic polyp. She complained of fatigue, occasional cramping and bloating abdominal discomfort, without any weight loss. Physical examination was normal. A gastric secretory study with pentagastrin infusion showed basal and peak acid outputs to be zero (gastric pHs of

Department of ${ }^{1}$ Gastroenterology, ${ }^{2}$ Pathology and ${ }^{3}$ Surgery, McGill University Health Centre, Montreal, Quebec

Correspondence and reprints: Dr Saul Katz, 687 Pine Avenue West, R2.28, Montreal, Quebec H3A 1A1. Telephone 514-842-1231, fax 514-843-1421,e-mail saul.katz@muhc.mcgill.ca

Received for publication September 15, 1998. Accepted June 9, 1999 

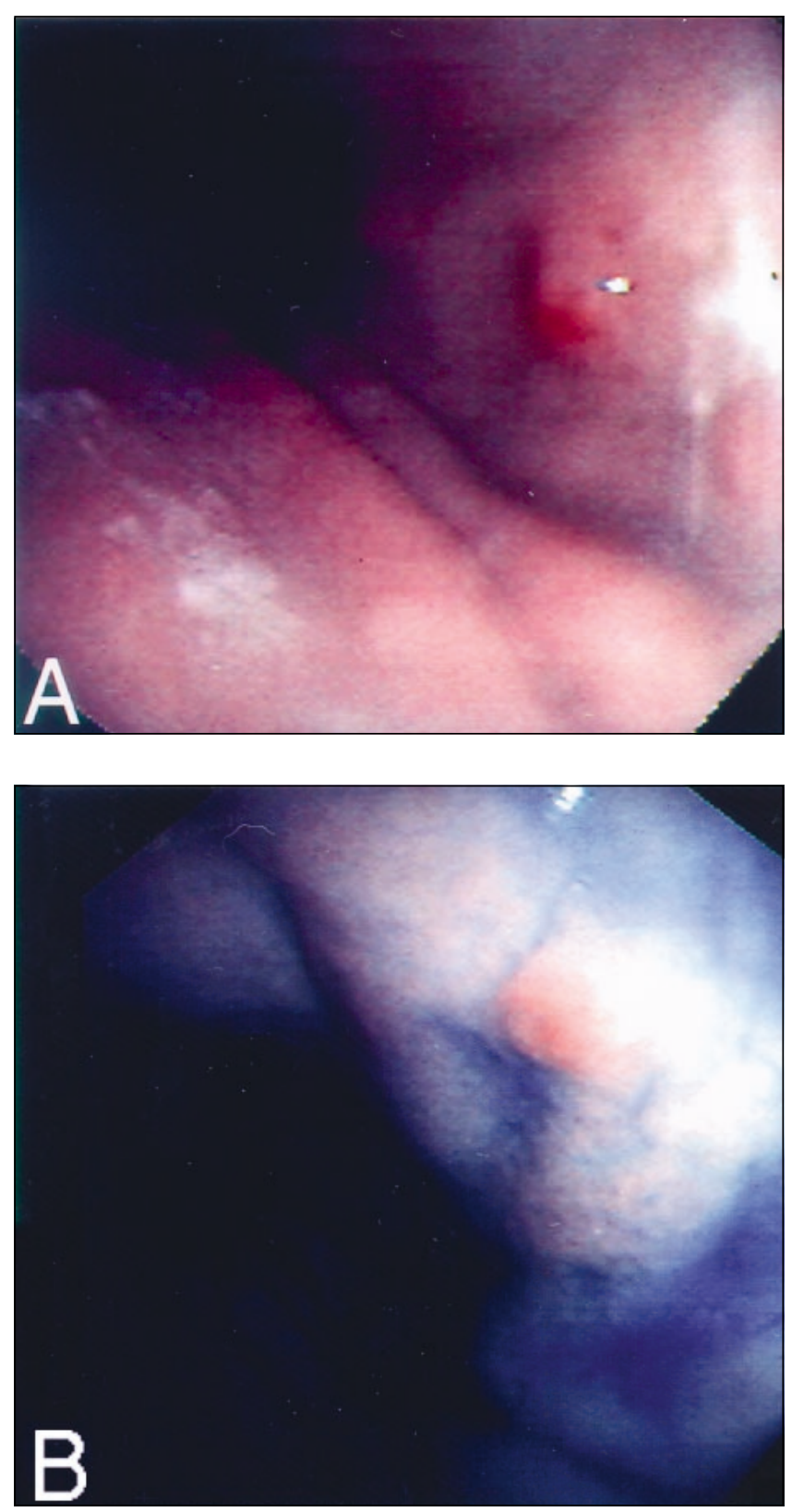

Figure 1) A Carcinoid tumour nodule in the gastric fundus as seen on gastroscopy. There is hyperemia and a small erosion at the apex of the nodule. B Carcinoid tumour nodule as seen on gastroscopy after spraying the mucosal surface with methylene blue

6.8 and 7.2, respectively), confirming the presence of achlorhydria. Serum gastrin at presentation was $1743 \mathrm{ng} / \mathrm{L}$ (normal 0 to $100 \mathrm{ng} / \mathrm{L}$ ).

An upper gastrointestinal series showed free gastroesophageal reflux and a normal gastric mucosa. Gastroscopy revealed mucosal atrophy and six small red nodules in the fundus, the largest being $0.5 \mathrm{~cm}$ with an eroded surface (Figure 1A). Methylene blue vital stain facilitated identification of these small nodules (Figure 1B). Multiple biopsies were taken.

Histological examination of the gastric mucosa revealed CAG with focal intestinal metaplasia (Figure 2A), enterochromaffin cell hyperplasia (Figure 2B) and tightly packed
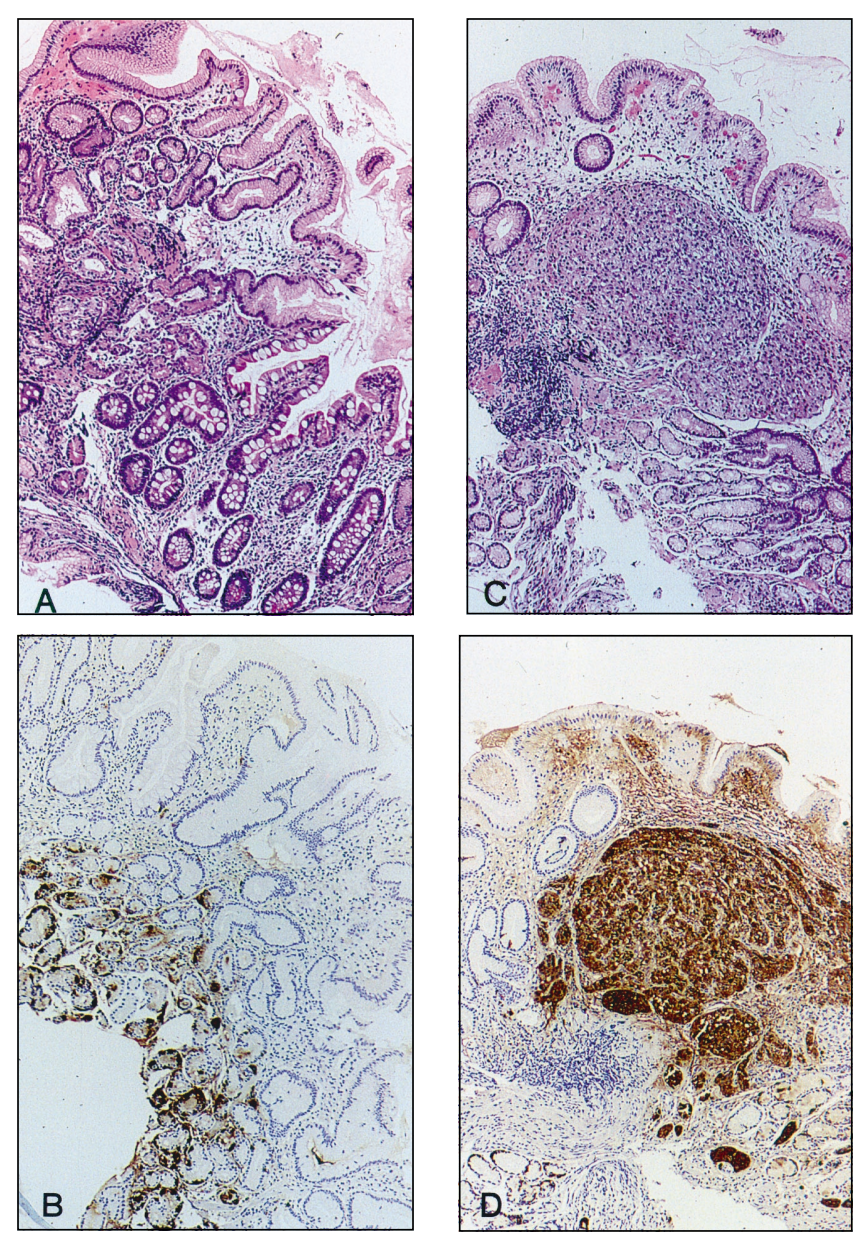

Figure 2) Histological and immunohistochemical preparations of the gastric mucosa from pre-antrectomy endoscopic biopsies. A Chronic atrophic gastritis with intestinal metaplasia. Hematoxylin and eosin, magnification $\times 100$. B Enterochromaffin cell hyperplasia as revealed by immunostain for chromogranin A. Immunoperoxidase reaction, magnification $\times 100$. C Intramucosal carcinoid tumour (microcarcinoid). Hematoxylin and eosin, magnification $\times 100$. D Intramucosal carcinoid tumour (microcarcinoid) as confirmed by immunostain for chromogranin A. Immunoperoxidase reaction, magnification $\times 100$

nests of neoplastic polygonal enterochromaffin cells confined to the mucosa. The latter areas corresponded to intramucosal carcinoid tumours or microcarcinoid tumours (Figure $2 \mathrm{C}$ ).

Histochemical staining for chromogranin A confirmed the diagnosis of carcinoid tumour (Figure 2D), which was further supported by the presence of numerous neurosecretory dense core granules, about $300 \mathrm{~nm}$ in diameter, as revealed by electron microscopy (Figure 3). The patient underwent an antrectomy with Billroth II anastomosis. Postoperative gastrin levels dropped to $63 \mathrm{ng} / \mathrm{L}$. Gastroscopy done one year after surgery revealed regression of the nodules. Two tiny nodules remained at six months, but biopsy did not reveal any carcinoid tumour. The postoperative course was complicated by severe bile reflux esophagitis, which was unresponsive to medical management. The patient underwent a Roux-en-Y gastrojejunostomy, which was successful in relieving bile reflux. Three and a half years after 


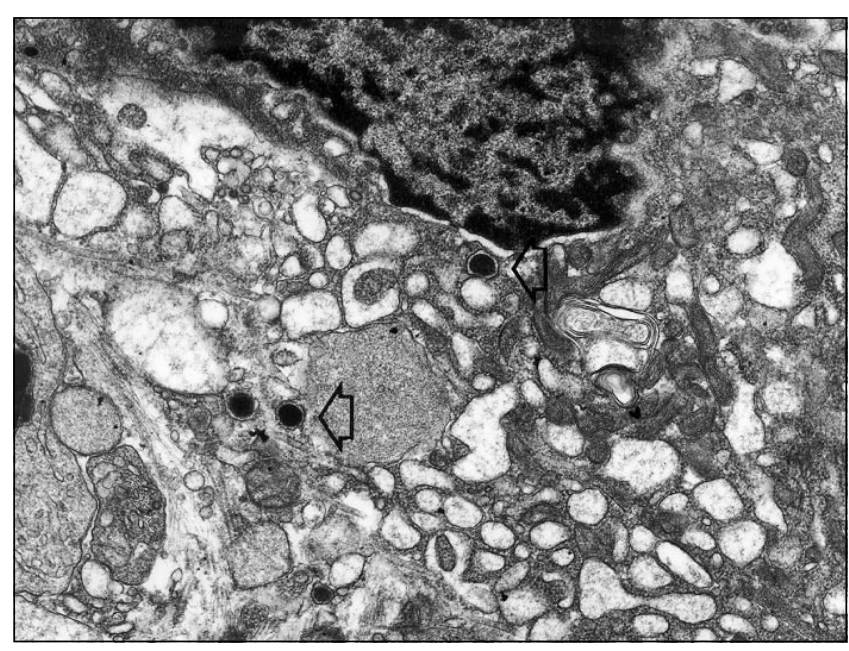

Figure 3) Electron microscopy of intramucosal tumour demonstrating neurosecretory granules (dense core vesicles) in the cytoplasm of a tumour cell (arrows). Magnification $\times 19,000$

antrectomy, the patient felt well. Follow-up gastroscopies and gastric biopsies every six months were negative for tumour until the most recent examination, when, although no nodules were seen endoscopically, biopsies revealed minute foci of microcarcinoid tumour. Serum gastrin levels, normal postoperatively, gradually increased to $246.6 \mathrm{ng} / \mathrm{L}$ three years after antrectomy (Figure 4).

\section{DISCUSSION}

PA patients have an increased prevalence of multiple cancers, including cancer of the stomach, esophagus and pancreas, myeloid leukemia and multiple myeloma, as well as cancer of the mouth, throat and colon (7). Carcinoid tumours of the stomach are of special interest because of their high prevalence in these patients, the mechanism of their pathogenesis and evolving concepts of management. However, the clinical setting should be extended to include all cases of autoimmune gastritis (type A gastritis) with achlorhydria. This should be distinguished from Helicobacter pylori-associated gastritis (type B gastritis), which has been identified as an independent risk factor for adenocarcinoma and mucosa-associated lymphoid tissue-type tumours of the stomach.

Carcinoid tumours of the stomach arising in a setting of type A atrophic gastritis should be distinguished from sporadic gastric carcinoid tumours and those occurring with Zollinger-Ellison syndrome and multiple endocrine neoplasia (MEN) type 1 (3). Kloppel and Clemens (3) classified gastric carcinoid tumours into four types. Type I tumours, those arising with CAG, represent $50 \%$ to $80 \%$ of all gastric carcinoid tumours, are in general smaller and usually, but not always, benign $(3,8)$. Rindi et al (8) identified 224 CAGassociated fundic carcinoid tumours, of which 17 (7.6\%) were metastatic (8).

Three other types of gastric carcinoid tumours have been described, all with a greater malignant potential. Type 2 tumours are not associated with hypergastrinemia but may pro-

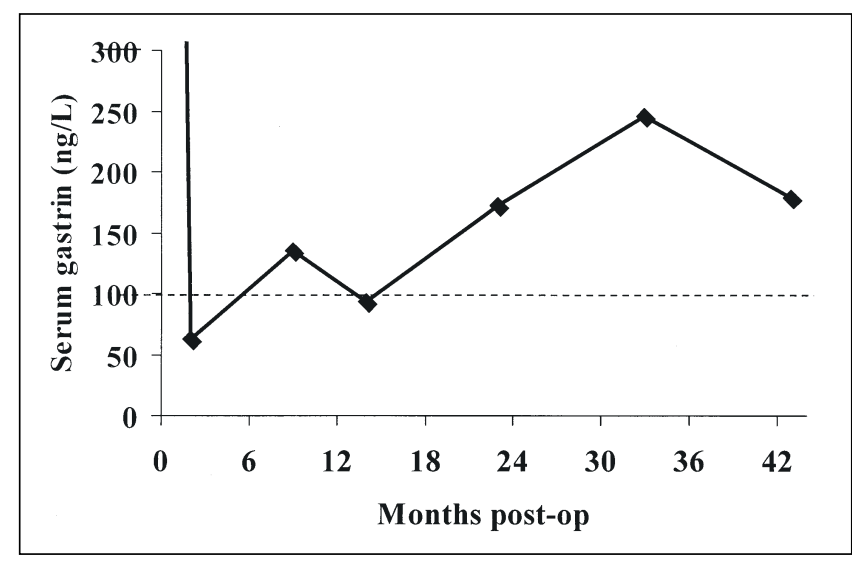

Figure 4) Serum gastrin levels during three and a half years of follow-up after antrectomy. Post-op Postoperation

duce a carcinoid syndrome and have a malignant potential as high as $26 \%$. Type 3 tumours are associated with ZollingerEllison Syndrome and MEN-1, are often multiple and metastasize in $20 \%$ of cases. Type 4 tumours are sporadic, solitary neoplasms that are not associated with any hormonal syndrome, are poorly differentiated and highly malignant, metastasizing in $90 \%$ of cases.

Gastric inflammation in PA leads to mucosal atrophy in the body and fundus of the stomach, and destruction of the acid-secreting parietal cells. The subsequent achlorhydria causes sustained high gastrin levels because of the absence of suppression of antral $\mathrm{G}$ cells by acid. Gastrin is a trophic hormone for the gastrointestinal tract. It has been shown to stimulate hyperplasia of the enterochromaffin-like (ECL) cells of the stomach. Rats rendered achlorhydric by high dose, prolonged omeprazole intake developed gastric carcinoid tumours (9). These early animal studies raised a concern for patients treated with long term proton pump inhibitors, but it has not been realized in humans because of either a lack of complete acid suppression or species differences. The exceedingly high serum gastrin levels in PA and the consequent persistent stimulation of the ECL cells result in their hyperplasia, and in some patients, carcinoid tumours $(10,11)$. In addition, some of the cytokine products of inflammation are cellular growth factors, which may play a role in the chronic stimulation of the ECL cells in the chronically inflammed gastric mucosa of PA (12).

Treatment of gastric carcinoids has evolved with time. Total gastrectomy is associated with significant morbidity and is an unnecessarily radical procedure given the low malignant potential of these tumours. Ahlman et al (6) suggested endoscopic treatment for type I gastric carcinoid tumours that are smaller than $1 \mathrm{~cm}$ and fewer than five in number, and antrectomy for larger or more numerous lesions. Ablating the individual lesions may not be practical because of their multiplicity, as well as the difficulty in identifying very small lesions, although vital stains such as methylene blue (Figure 1B) may be helpful (13).

Microscopic foci of carcinoid tumours such as those identified in our case and others (Table 1) are not detectable by 
TABLE 1 Antrectomy to induce regression of multicentric gastric
carcinoid tumours

\begin{tabular}{lccc}
\hline Author (reference) & Cases & Success & Gastrectomy \\
\hline Ahlman et al (6) & 4 & 4 & 0 \\
Hirschkowitz et al (14) & 3 & 3 & 0 \\
Richards et al (15) & 1 & 1 & 0 \\
Olber et al (16) & 1 & 1 & 0 \\
Morgan et al (17) & 1 & - & 1 \\
Kern et al (18) & 1 & - & 1 \\
Eckhauser et al (19) & 2 & 1 & 1 \\
Kaplan et al (12) & 1 & 1 & 0 \\
Total & 15 & 11 & 3 \\
\hline
\end{tabular}

direct vision (endoscopic or at surgery). The best approach may be antrectomy, which removes the hormonal support and potentially allows the tumours to regress (1-6,14-19). We reviewed the literature and found complete regression of multicentric gastric carcinoid tumours associated with PA after antrectomy in 11 of 15 cases $(6,12,14-19)$. Five cases had recurrent or residual tumour at follow-up $(6,14,17-19)$, at least three of which proceeded to total gastrectomy (Table 1).

The outcome of this review and our own results indicate that a good response can be achieved with antrectomy in carcinoid tumours associated with CAG and PA. More radical surgery should be reserved for sporadic tumours or those associated with Zollinger-Ellison syndrome or MEN, given their greater potential for malignancy. The overall potential success rate of antrectomy ( $75 \%$ including this case report) might be even higher ( 11 of 13) because at least two of the above cases proceeded to total gastrectomy without confirmed evidence of carcinoid metastases $(17,18)$. It should be recognized that standard antrectomy, especially in the elderly and in the setting of chronic gastritis, may leave behind pyloric mucosa containing gastrin-producing cells. The gastric incisura does not necessarily correspond with the transition from pyloric to fundic mucosa, and with pyloric metaplasia in chronic gastritis, especially in the elderly, the junctional zone moves proximally toward the cardia (20). Review of the antrectomy specimen in our case showed that the distal margin was in the duodenum; therefore, there was no 'retained antrum' in the traditional sense. However, the pathologist noted in his report of the resected antrum that "...the proximal margin passes through interfaces of pyloric antral and body type mucosa. Therefore, while the anatomic antrum comprising the large majority of G-cells has been resected, some G-cell containing areas probably were left behind with the upper stomach". Indeed, these residual G cells, perhaps through hyperplasia, caused the serum gastrin to increase from a postoperative normal level to $246.6 \mathrm{ng} / \mathrm{L}$ three years later. Whether the microscopic foci of carcinoid tumours found three and a half years after surgery represent random samples that, by chance, were missed on previous biopsies or whether the malignant process is restarting under the influence of rising gastrin levels will only be determined by longer follow-up. As in our case, two of the three patients reported by Hirschowitz et al (14) had recurrent 'microscopic tumourlets' 14 to 18 months after antrectomy, having had negative biopsies before. One patient's serum gastrin increased to $330 \mathrm{ng} / \mathrm{L}$ a year after surgery. Subsequent biopsies in both patients were negative for carcinoid tumour.

An alternative explanation for failure of complete regression of the carcinoid tumour after antrectomy is that more dysplastic foci of the carcinoid tumour may regress less readily, or not at all. Solcia et al (10) distinguished simple hyperplasia, where the increased ECL cells can be in linear arrays or form minute micronodules (linear or nodular hyperplasia), from dysplasia, where the nodules are over $150 \mu \mathrm{m}$ in diameter and/or invasion is indicated by stromal reaction in the lamina propria or the presence of carcinoid tumours beyond the muscularis mucosa. Disappearance of hyperplastic rather than dysplastic cells may be responsible for the rapid regression of gastric carcinoid tumours after antrectomy.

We cannot be certain what the ideal treatment is for multifocal gastric carcinoid tumours. Some authors have considered the tumours to be biologically benign and asymptomatic and, therefore, not requiring excisional surgery. However, carcinoid tumours can metastasize in the animal model. More importantly, in humans, multifocal gastric carcinoid tumours can metastasize to both local lymph nodes and distant sites in up to $7.6 \%$ of cases (8). Therefore, if even a small number have true malignant potential, overly conservative treatment is not acceptable.

Antrectomy may be the most appropriate treatment for multifocal gastric carcinoid tumours. The tumours seem to require the very high gastrin hormonal support to develop, and tumour nodules have been observed by us and others to regress after antrectomy. Whether the observation of microscopic foci of carcinoid tumour more than a year after antrectomy represents de novo recurrence of tumour because of incomplete antrectomy or the chance pickup of regressing tumour cannot be answered at this time. Caution should be exercised at the time of surgery, perhaps by using frozen sections of the proximal lesser curve to ensure complete functional antrectomy.

Almost half of the 15 reported cases showed microcarcinoid tumours on follow-up gastroscopy from 12 to 18 months postoperatively that eventually regressed. Regression may be a gradual process that takes a considerable length of time. Postoperative screening endoscopy with multiple biopsies at regular intervals, perhaps every six months, may be appropriate. Sporadic gastric carcinoid tumours or those associated with Zollinger-Ellison syndrome or MEN should have more radical surgery, given their greater potential for malignancy.

Nonsurgical approaches to suppress gastrin secretion or otherwise disrupt the achlorhydria-hypergastrinemia-ECL proliferation cycle to induce gastric carcinoid regression are unproven or not practical. Somatostatin analogues, although potentially effective, are not practical because of their expense. Early reports aimed at treating the inflammatory gastritis of PA with steroids or azathioprine $(21,22)$ 
showed that it was possible to facilitate regeneration of the parietal cell mass, increase acid production and in some patients induce regression of intestinal metaplasia. Unfortunately this effect persisted only as long as the steroid or immunosuppressives were given. Chronic steroid use does not seem to be a feasible alternative.

Regular gastroscopic screening is advised in patients with PA and CAG to detect early gastric carcinoid tumours and even gastric cancer. Antrectomy appears to be a safe and effective treatment for early gastric carcinoid tumours.

\section{REFERENCES}

1. Sjoblom SM, Sipponen P, Miettinen, et al. Gastroscopic screening for gastric carcinoids and carcinoma in pernicious anemia. Endoscopy 1988;20:52-6.

2. Rappel S, Altendorf-Hormann A, Stolte M. Prognosis of gastric carcinoid tumours. Digestion 1995;56:455-62.

3. Kloppel G, Clemens A. The biological relevance of gastric neuroendocrine tumours. Yale J Biol Med 1996;69:69-74.

4. Creutzfeldt W. The achlorhydria-carcinoid sequence: Role of gastrin. Digestion 1988;39:61-79.

5. Borch K, Renvall H, Liedberg G. Gastric endocrine cell hyperplasia and carcinoid tumours in pernicious anemia. Gastroenterology 1985;88:638-48.

6. Ahlman H, Kolyby L, Lundell L, et al. Clinical Management of carcinoid tumors. Digestion 1994;55(Suppl 3):77-85.

7. Hsing AW, Hansson L, McLaughlin JK, et al. Pernicious anemia and subsequent cancer, a population-based cohort. Cancer 1993;71:745-50.

8. Rindi G, Luinetti O, Cornaggia M, Capella C, Solcia E. Three subtypes of gastric argyrophil carcinoid and the gastric neuroendocrine carcinoma: a clinicopathologic study. Gastroenterology 1993;104:994-1006.

9. Ekman L, Hansson E, Havu N, Carlsson E, Lundberg C. Toxicological studies on Omeprazole. Scand J Gastroenterol Suppl 1985;108:53-69

10. Solcia E, Fiocca R, Villani L, et al. Morphology and pathogenesis of endocrine hyperplasias, precarcinoid lesions, and carcinoids arising in chronic atrophic gastritis. Scand J Gastroenterol Suppl 1991;180:146-59.

11. Solcia E, Rindi G, Silini E, Villani L. Enterochromoffin-like (ECL) cells and their growth: relationships to gastrin, reduced acid secretion and gastritis. Baillieres Clin Gastroenterol 1993;7:149-65.

12. Case records of the Massachusetts General Hospital. Weekly clinicopathological exercises. Case 9-1997. A 39-year-old woman with pernicious anemia and a gastric mass. N Engl J Med 1997;336:861-7.

13. Fennerty M. Should chromoscopy be part of the "proficient" endoscopist's armamentarium? Gastrointest Endosc 1998;47:313-5.

14. Hirschowitz BI, Griffith J, Pellegrin D, Cummings OW. Rapid regression of enterochromaffinlike cell gastric carcinoids in pernicious anemia after antrectomy. Gastroenterology 1992;102:1409-18.

15. Richards AT, Hinder RA, Harrison AC. Gastric carcinoid tumours associated with hypergastrinaemia and pernicious anaemia regression of tumours by antrectomy. A case report. S Afr Med J 1987;72:51-3.

16. Olber L, Lundell L, Sundler F, et al. Antrectomy in a patient with ECL-cell gastric carcinoids and pernicious anemia. Gastroenterol Int 1988;1(Suppl):340. (Abst)

17. Morgan JE, Kaiser CW, Johnson W, et al. Gastric carcinoid (gastrinoma) associated with achlorhydria (pernicious anemia). Cancer 1983;51:2332-40.

18. Kern SE, Yardley JH, Lazenby AJ, et al. Reversal by antrectomy of endocrine cell hyperplasia in the gastric body in pernicious anemia: a morphometric study. Mod Pathol 1990;3:561-6.

19. Eckhauser FE, Lloyd RV, Thompson NW, et al. Antrectomy for multicentric, argyrophil gastric carcinoids: a preliminary report. Surgery 1988;104:1046-53.

20. Owen DA. Normal histology of the stomach. Am J Surg Pathol 1986;10:48-61

21. Wall AJ, Whittingham S, MacKay IR, et al. Prednisolone and gastric atrophy. Clin Exp Immunol 1968;3:359-66.

22. Jorge AD, Sanchez D. The effect of azathioprine on gastric mucosal histology and acid secretion in chronic gastritis. Gut 1973;14:104-6. 


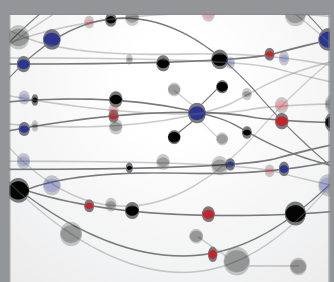

The Scientific World Journal
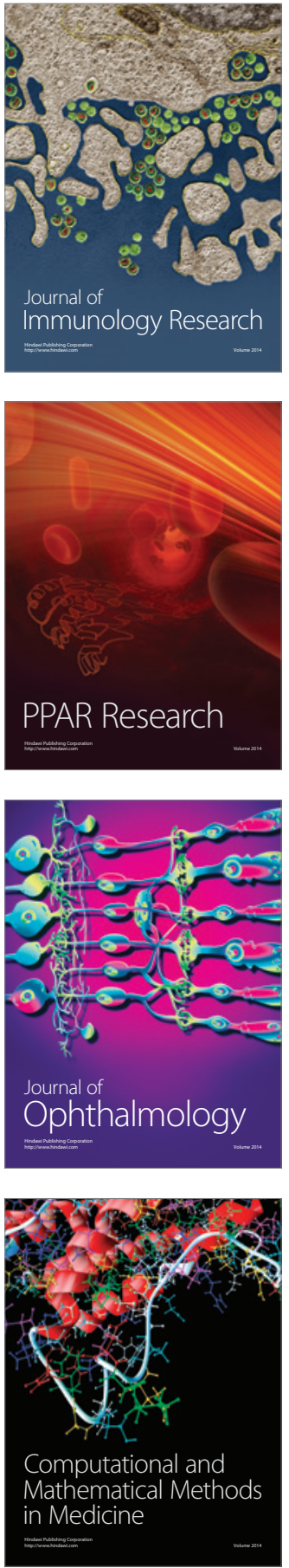

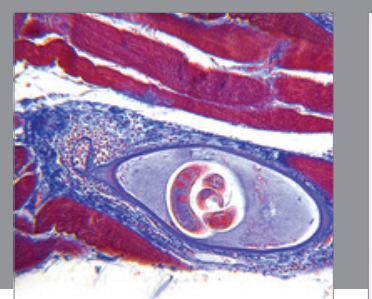

Gastroenterology Research and Practice

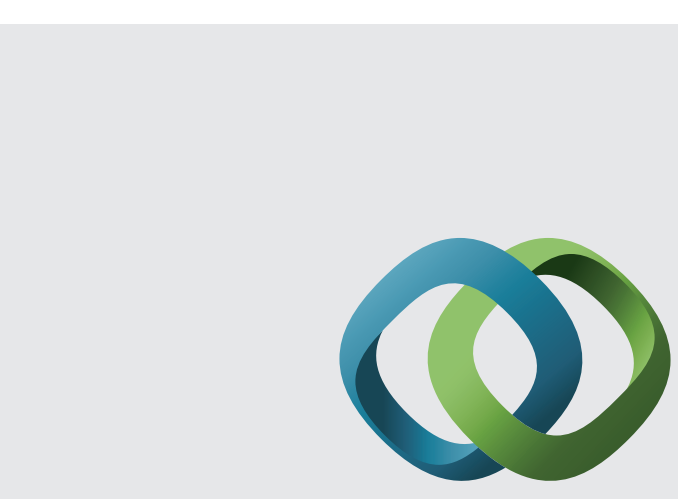

\section{Hindawi}

Submit your manuscripts at

http://www.hindawi.com
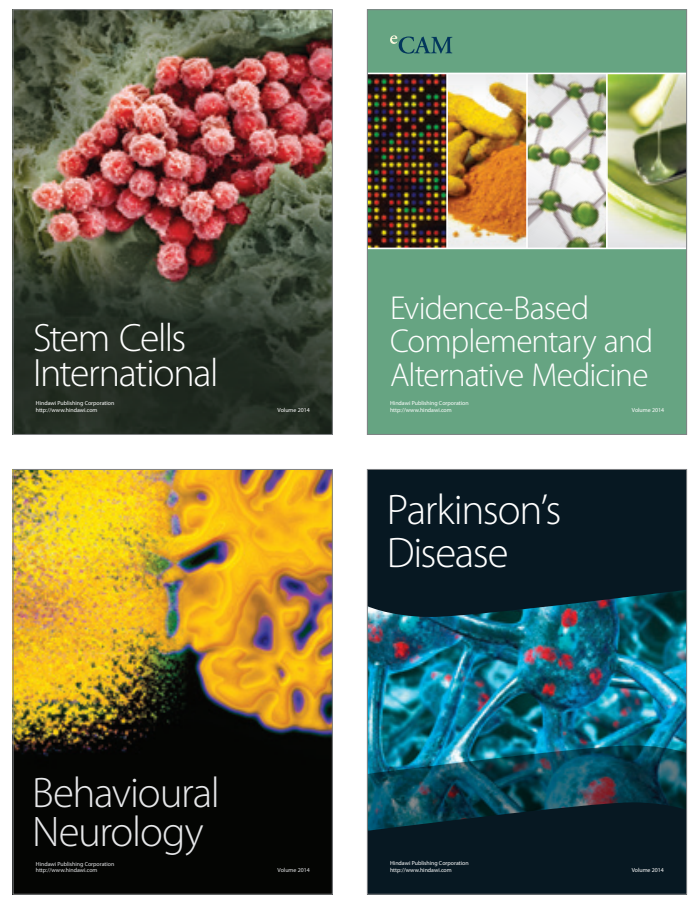
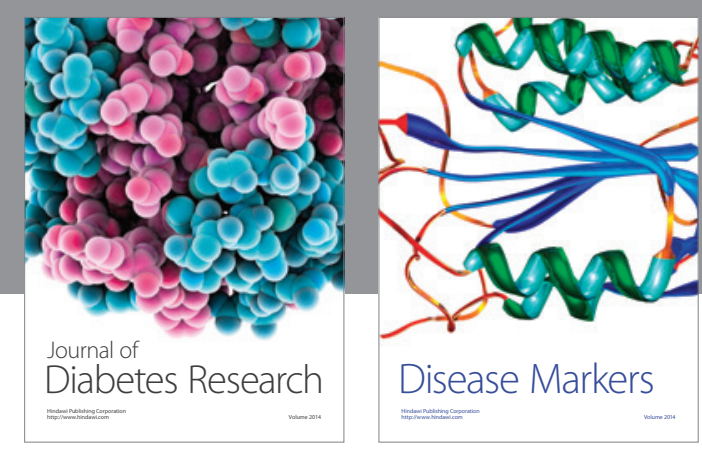

Disease Markers
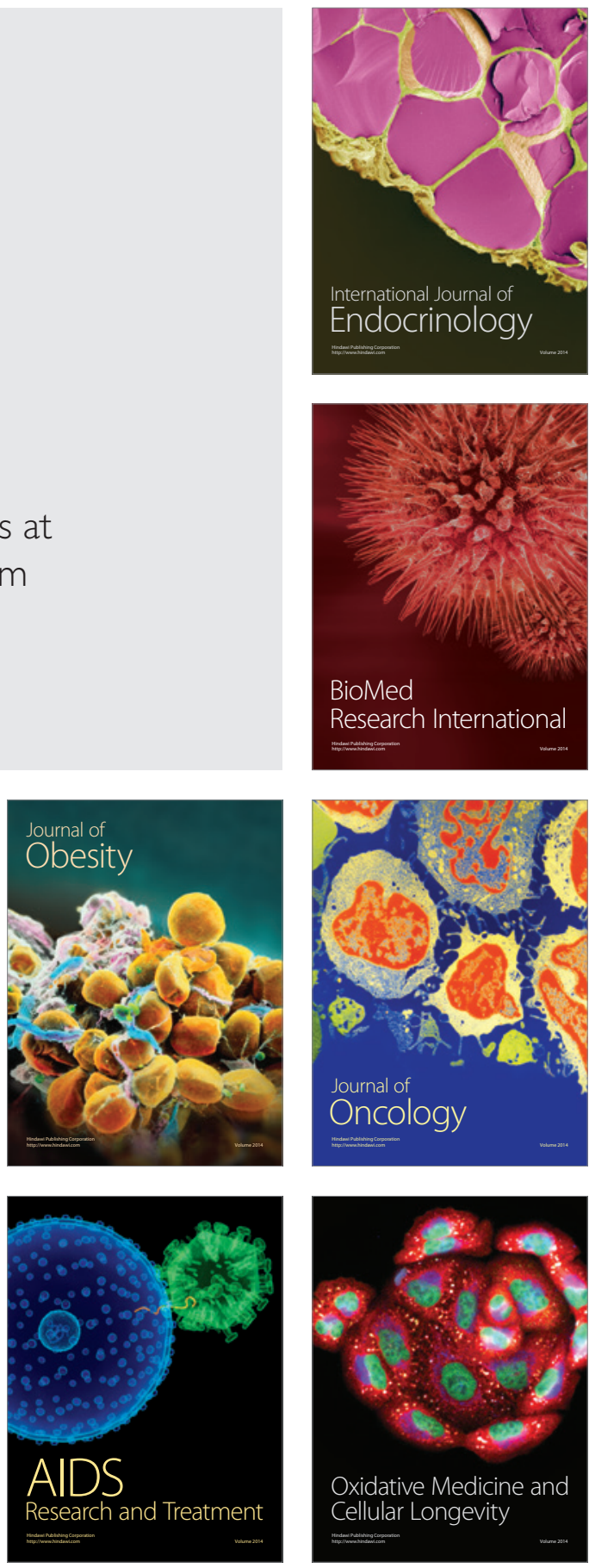